\title{
Loading capacity of yielding connections used in steel arch roadway supports
}

\author{
P. Horyl VSB-Technical University of Ostrava, Czech Republic \\ R. Snuparek Institute of Geonics, Czech Republic \\ M. Hlavackova VSB-Technical University of Ostrava, Czech Republic
}

\begin{abstract}
Yielding steel arch supports of roadways are widely used in coal mines. These supports consist of several segments joined by friction bolt connections. The loading capacity and pliability (ability to accept deformations of surrounding rock mass) of the arch support is greatly influenced by the function of the connections and, in particular, the tightening of the bolts. Representative laboratory experiments are difficult to perform and it is only through expansive research on the entire support structure that relevant knowledge on these parameters can be obtained. This contribution deals with the computer modelling of the behaviour of the yielding bolt connections for different torques with the aim of determining the loadbearing capacity. Another parameter that significantly affects the loading capacity is the value of the friction coefficient of the contacts between the elements of the joints. For computer modelling, the ANSYS software and the finite element method was used. The solution is non-linear because of the bi-linear material properties of steel and the large deformations. The calculation also defines the weakest part of the joint's structure based on stress analysis.
\end{abstract}

\section{Introduction}

Open floor yielding arches are used primarily in coal mines. These supports consist of several segments joined by friction bolts (Figure 1). The loading capacity of a friction connection (maximal value of normal forces capable of being withstood by the connection without slip of the segments) plays an important role in the static design of arch supports. The construction of the connection with regard to the strength of its different parts and the tightening of the screws introduce meaningful technical aspects regarding the function of yielding supports. Constructions of yielding connections have to fulfil two requirements. The clamping force has to be sufficiently high to provide a safe load bearing capacity of the arch but not so high to eliminate yielding. There is not a general consensus regarding the optimal value of the torque moment of tightening bolts (Podjadtke et al., 2009). Therefore, we modelled the most widely applied screw connection, which has three pairs of bolts, used in Germany, Poland and the Czech Republic (Junker, 2009) (Figures 2 and 3). We investigated the behaviour and condition of the individual parts for three values of tightening moment and also the relation between the value of screw tightening and load-bearing capacity of the connection for different friction coefficients. 


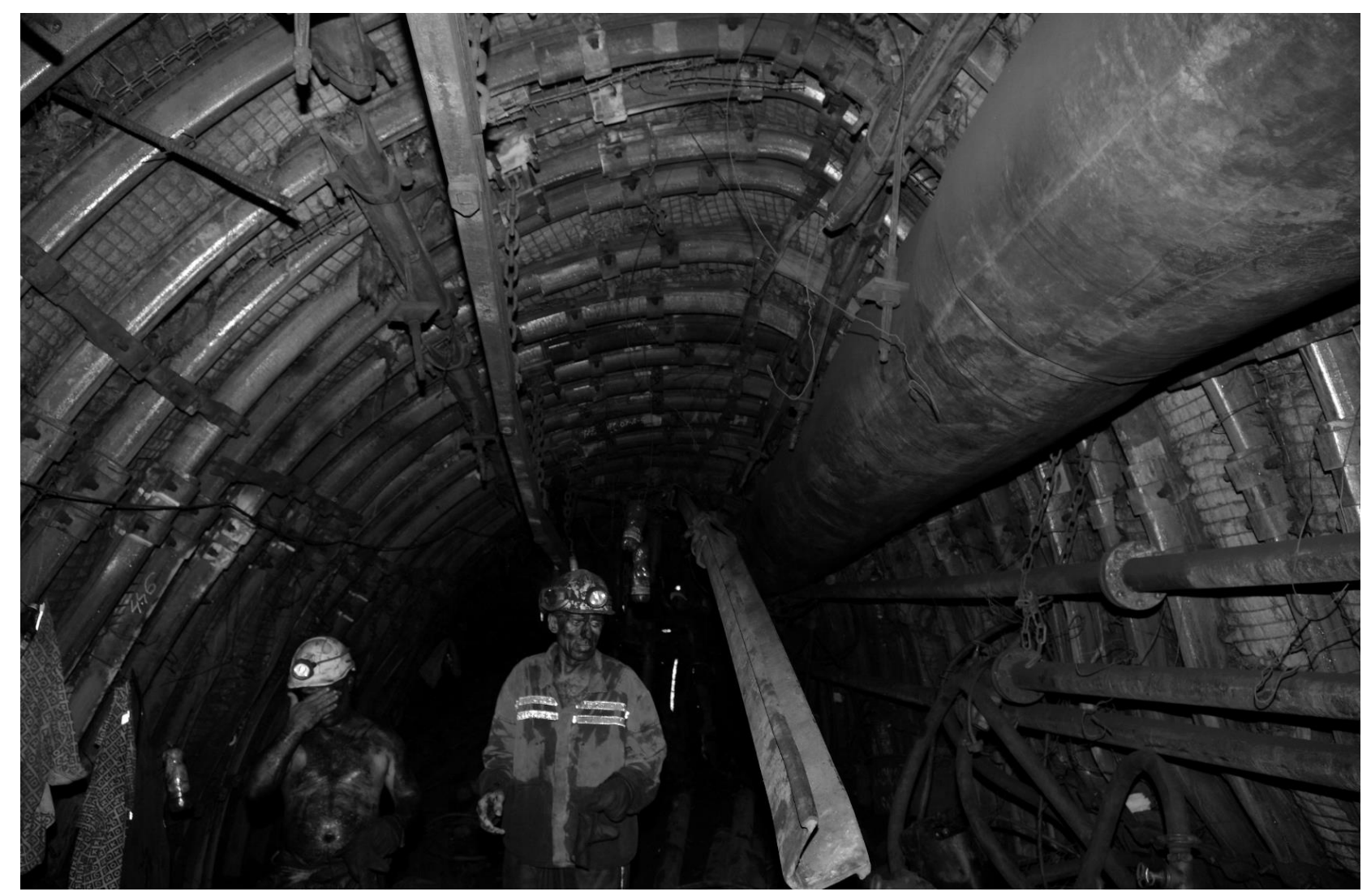

Figure 1 Roadway with four segment arch support

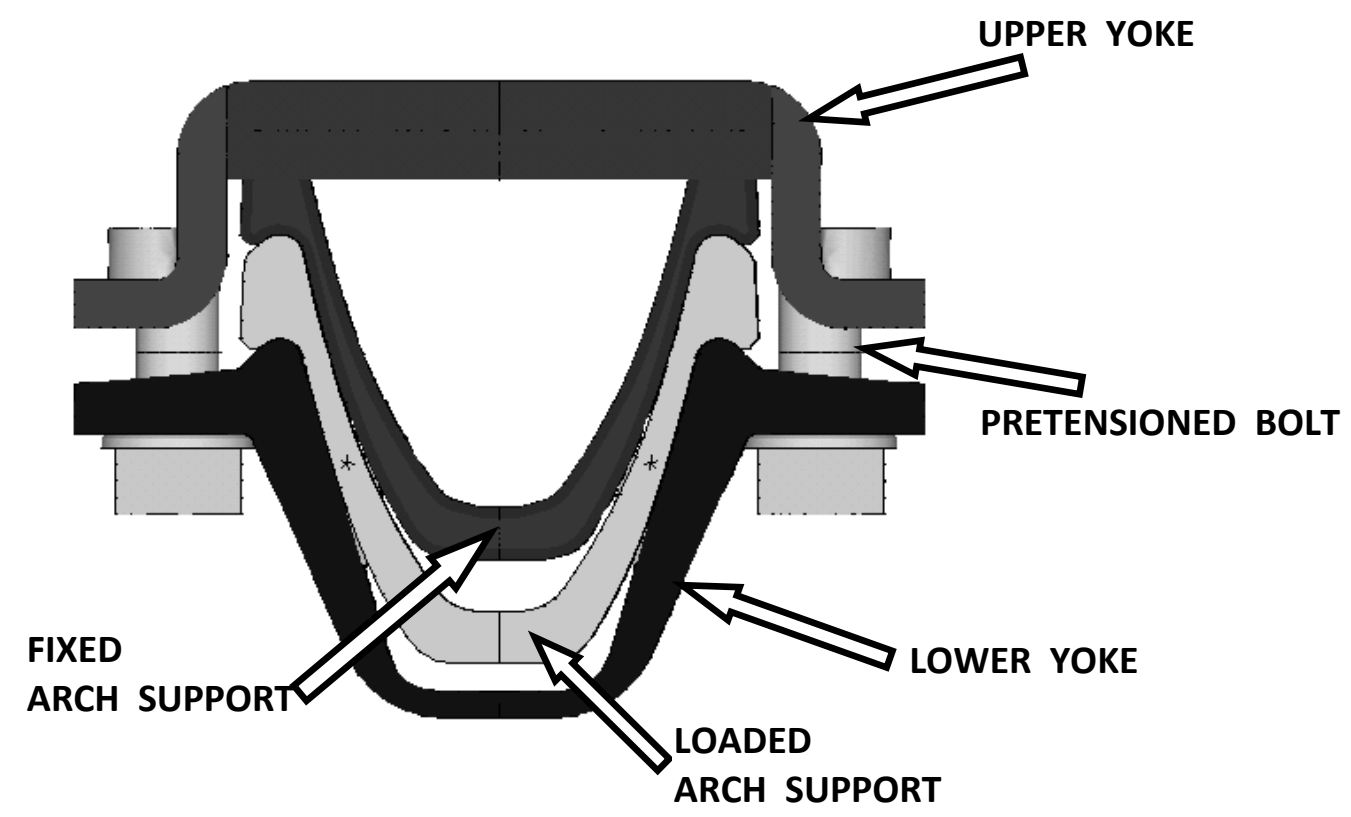

Figure 2 Yielding connection, front view 


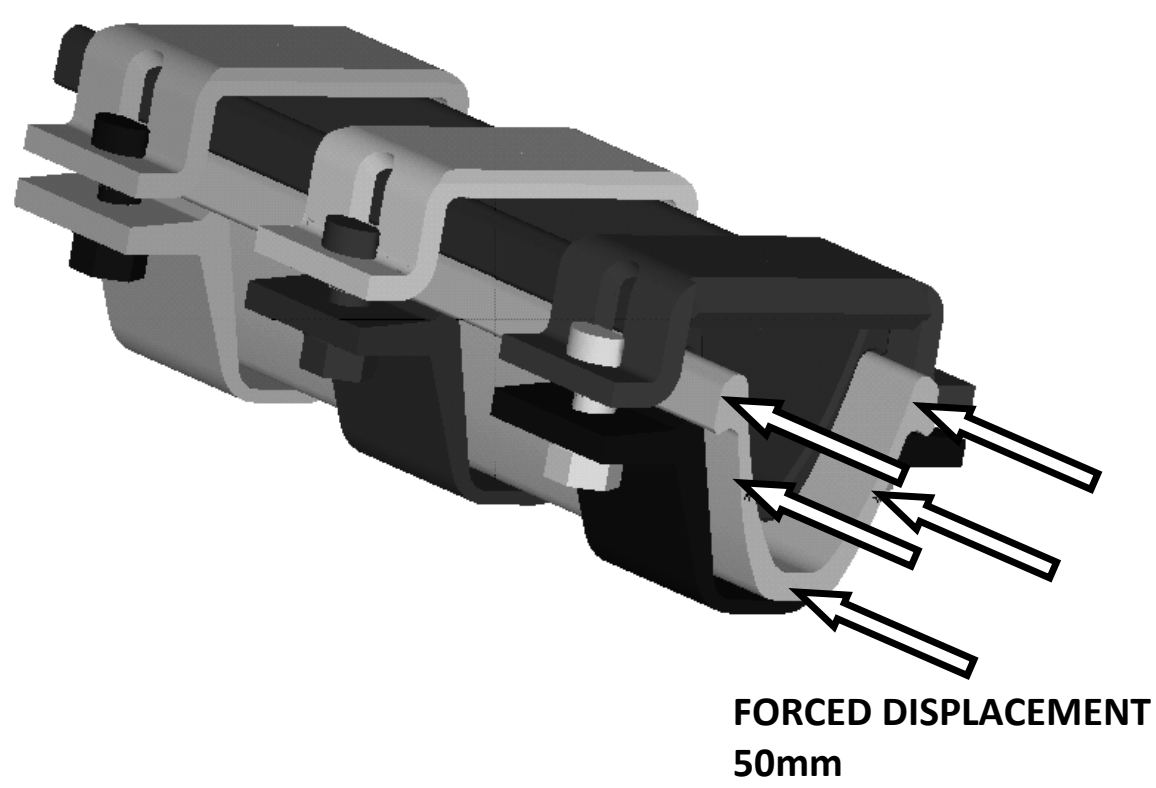

Figure 3 Yielding connection, 3D view

\section{Methodology}

Computer modelling of the clamp connection was performed using the ANSYS finite element software (ANSYS Release 14.0, 2011). The task of finding a clamp static loading capacity was a complex non-linear structural problem (Horyl and Snuparek, 2012), because we have large displacements and strains, nonlinear steel properties and many points of contact. Large displacements mean that the stiffness matrix of the whole structure depends on unknown deformation parameters. To model the non-linear material behaviour, bi-linear material properties were used, with three values: $\mathrm{E}$, Young's modulus of elasticity; $\sigma_{\mathrm{y}}$, yielding stress; and $\mathrm{E}_{\mathrm{T}}$, tangent modulus of plasticity. Our structure has three kinds of material (Table 1).

\section{Table 1 Material property of steel parts}

\begin{tabular}{cccc}
\hline Structure Part & $\begin{array}{c}\text { Moung's Modulus } \\
\text { of Elasticity } \\
\text { E (MPa) }\end{array}$ & $\begin{array}{c}\text { Yielding Stress } \\
\sigma_{\mathrm{y}}(\mathrm{MPa})\end{array}$ & $\begin{array}{c}\text { Tangent Modulus } \\
\text { of Plasticity } \\
\mathbf{E}_{\mathrm{T}}(\mathrm{MPa})\end{array}$ \\
\hline Steel support & 200,000 & 350 & 1,680 \\
Upper yoke and lower yoke & 295 & 1,783 \\
High strength connecting screw & & 640 & 2,170 \\
\hline
\end{tabular}

The geometry of the computer model was created from designs of all four parts of the structure. It was made in Workbench ANSYS 14.0. Because all boundary conditions were symmetric we created only one half of structure (Figure 4). Discretisation was done with solid, contact and pretensioned bolt elements (Table 2). 
Table 2 Finite elements used

\begin{tabular}{ccc}
\hline Type of Elements & ANSYS Finite Elements & Number of Elements \\
\hline Solid elements & SOLID186, SOLID187 & 75,941 \\
Contact elements & CONTA174, Targe170 & 26,311 \\
Pretensioned bolts & PRETS179 & 3 \\
\hline
\end{tabular}

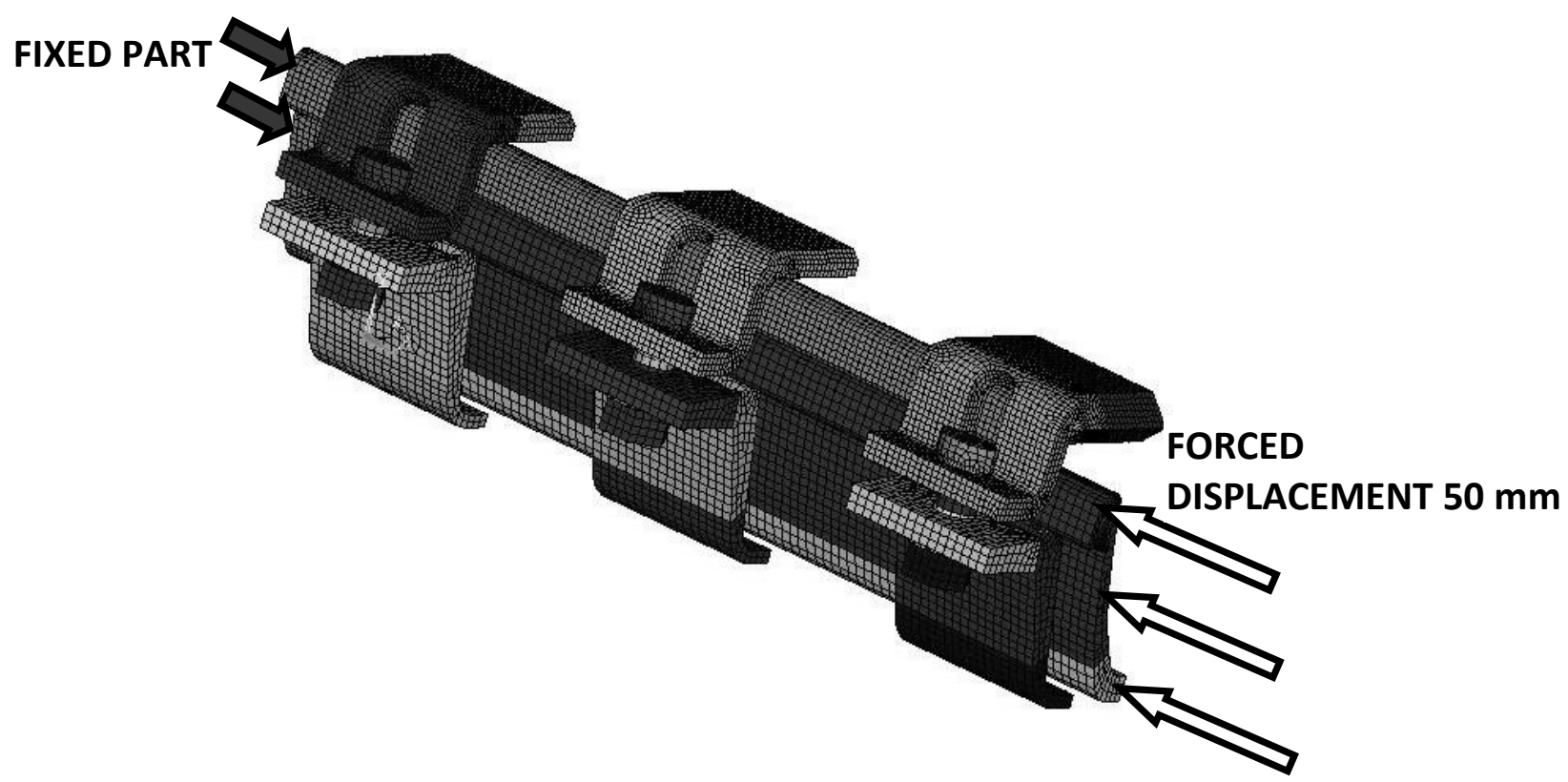

\section{Figure 4 Mesh of finite elements}

The total number of structural elements was 75,941 ; there were 308,643 nodes and the middle size of the elements of the mesh was $6 \mathrm{~mm}$ with finer remeshing in contact areas. The number of equations was 920,035 . The number of equations is the number of unknown deformation parameters of the system. The load was divided into two loading steps: the pretension of connecting bolts and the deformation loading $50 \mathrm{~mm}$ of one support. The second support was fixed (Figures 2, 3 and 4). The three torque values that were applied to the screws were: 350,400 and $450 \mathrm{Nm}$. These torques correspond to the values of the preload forces: $100,966 \mathrm{~N}, 115,390 \mathrm{~N}$ and 129,814 N. External torque values mainly affect the value of the loading capacity coefficient of friction in the contact pairs. This is why the calculations were performed with a coefficient of friction ranging from 0.12 to 0.32 in steps of 0.04 . The full Newton-Raphson method was chosen for the solution. The calculations were carried out on a computer of the Supercomputing Centre VSB-Technical University of Ostrava; the number of cores used was nine and one calculation took 11-15 hours. 


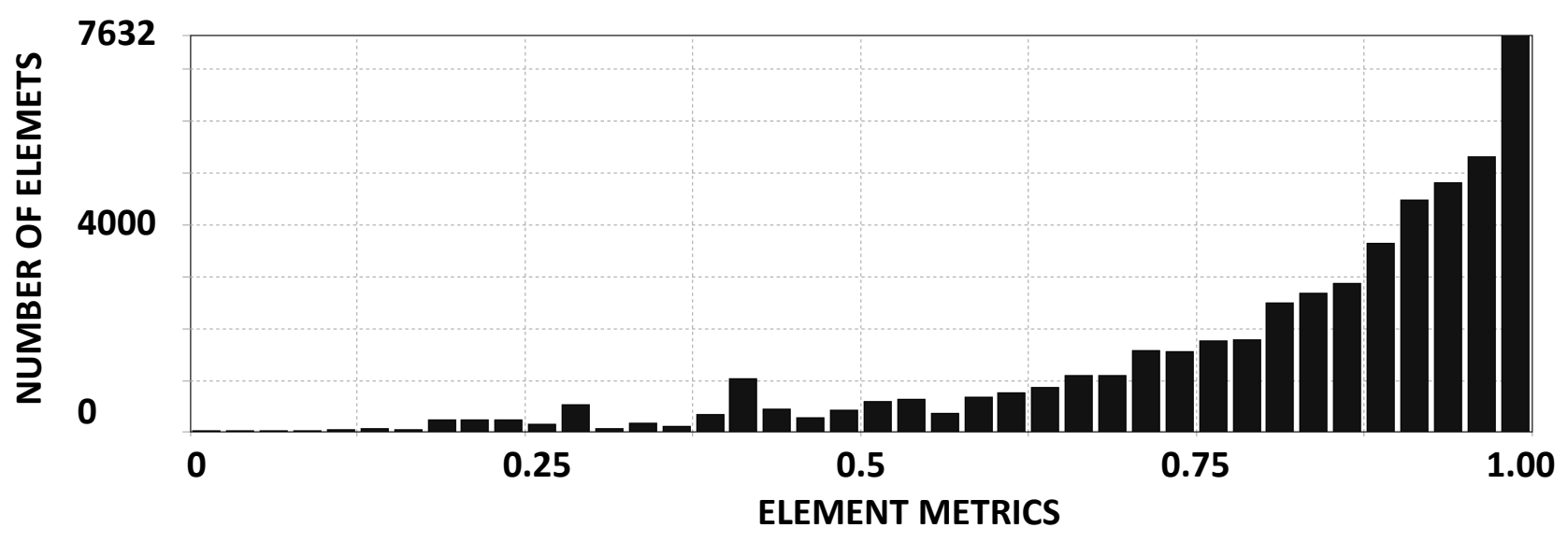

\section{Figure 5 Mesh quality of finite elements}

The quality of mesh was checked by element metrics (Figure 5). The element metrics option provides a composite quality metric that ranges between 0 and 1 . This metric is based on the ratio of the volume to the edge length for a given element. A value of 1 indicates a perfect cube or square, while a value of 0 indicates that the element has a zero or negative volume. The average of mesh metrics is 0.704 which means a good quality of mesh.

\section{$3 \quad$ Results}

The important factors for the assessment of mechanical structures after the loading are primarily: total displacement, value equivalent plastic strain $\varepsilon_{\mathrm{pl}}$ and Von Mises Stress $\sigma_{\mathrm{e}}$. Equivalent stress (also called Von Mises Stress) is often used in design work because it allows any arbitrary three-dimensional stress state to be represented as a single positive stress value. Equivalent stress is part of the maximum equivalent stress failure theory used to predict yielding in a ductile material. The equivalent plastic strain gives a measure of the amount of permanent strain in an engineering body. The equivalent plastic strain is calculated from the component plastic strain (ANSYS Release 14.0, 2011).

\subsection{Load step one - implementation of bolt preload}

Deformed structure after tightening the screws with torque of $450 \mathrm{Nm}$ is shown in Figure 6 . The largest displacement was found at the end of the upper yoke and amounted to $10.7 \mathrm{~mm}$. Although the value is significant, it does not affect behaviour of the joint and its yielding parameters. The results for the first preload step are presented in Table 3. 

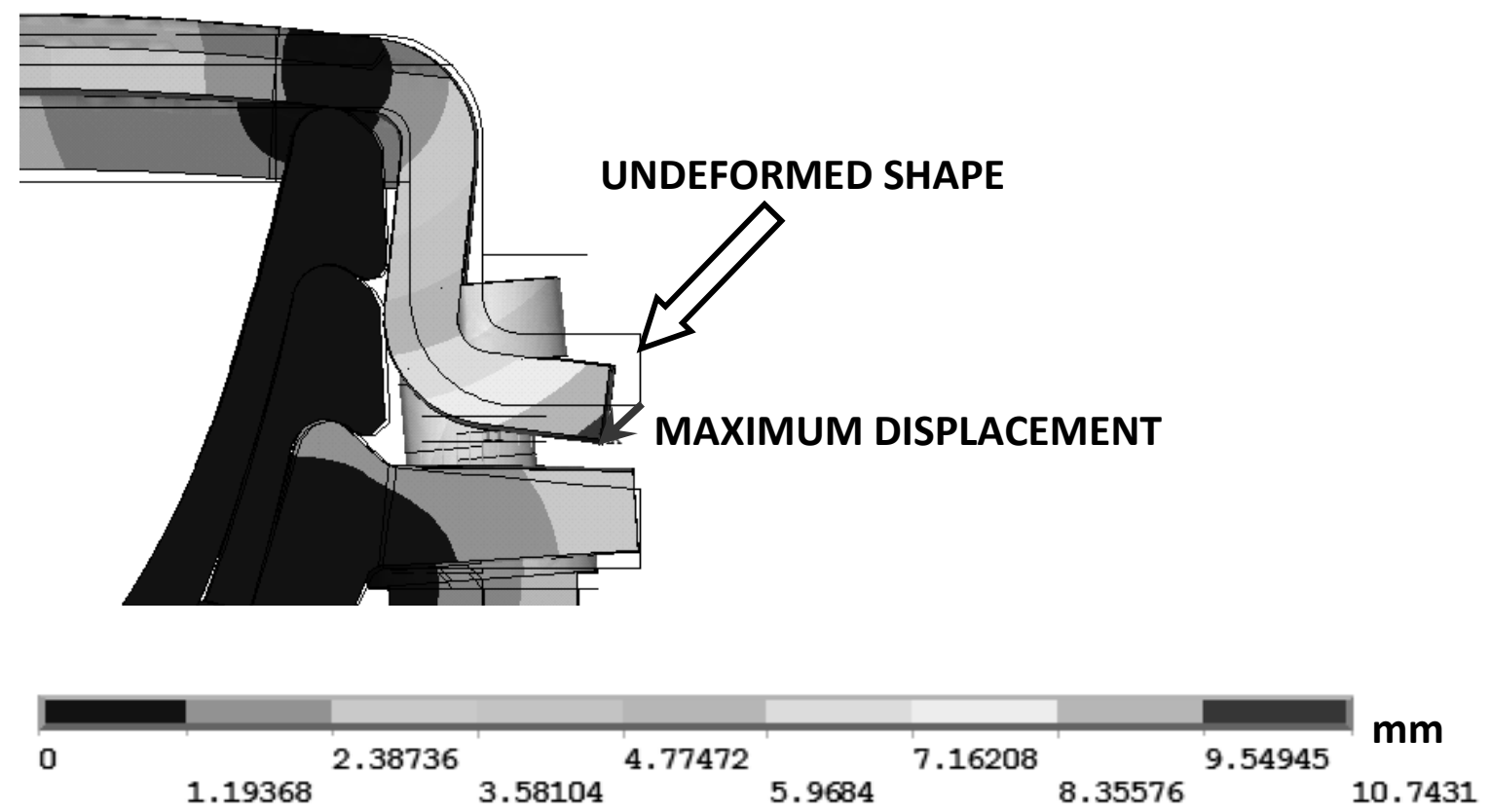

\section{Figure 6 Deformed structure, place of maximum deformation}

\section{Table 3 Results from bolt preload}

\begin{tabular}{ccccc}
\hline \multicolumn{2}{c}{ Description of the Variables } & \multicolumn{3}{c}{ Values } \\
\hline \multicolumn{2}{c}{ Torque $(\mathrm{Nm})$} & 350 & 400 & 450 \\
\multicolumn{2}{c}{ Maximum displacement $(\mathrm{mm})$} & 8.1 & 9.2 & 10.7 \\
\multirow{2}{*}{ Support } & $\sigma_{\mathrm{e}}(\mathrm{MPa})$ & 409 & 414 & 402 \\
& $\varepsilon_{\mathrm{pl}}(1)$ & 0.005 & 0.01 & 0.03 \\
Upper yoke & $\sigma_{\mathrm{e}}(\mathrm{MPa})$ & 572 & 623 & 710 \\
& $\varepsilon_{\mathrm{pl}}(1)$ & 0.16 & 0.183 & 0.24 \\
Lower yoke & $\sigma_{\mathrm{e}}(\mathrm{MPa})$ & 326 & 344 & 363 \\
& $\varepsilon_{\mathrm{pl}}(1)$ & 0.02 & 0.03 & 0.04 \\
Bolts & $\sigma_{\mathrm{e}}(\mathrm{MPa})$ & 1064 & 1125 & 1254 \\
& $\varepsilon_{\mathrm{pl}}(1)$ & 0.197 & 0.22 & 0.28 \\
\hline
\end{tabular}

It should be noted that all parts of the clamp exceeded the yield point, which means that, even after unloading, permanent deformation remains in the structure. As will be discussed below, the deformation usually affects only a very small area, which should not affect the functionality of the coupling. The locations of the small areas of yielding in the steel support are shown in Figure 7. Yielding in the upper yoke occurs in small areas in contact with the head bolt (Figure 8). Although, the value of equivalent plastic strain is high, only small plastic dimples arise in these areas. Few intensive areas of yielding occur on the lower yoke (Figure 9). A high degree of yielding occurs on the bolt but it is only a small area that is in contact with the screw head (Figure 10). 


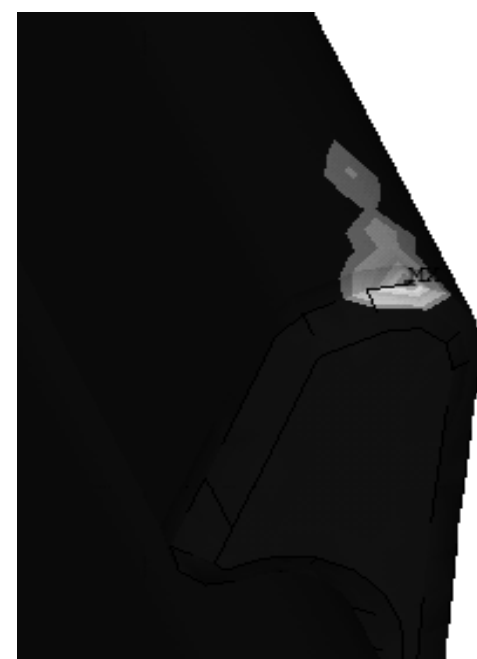

Figure 7 Plastic areas on steel support, $\varepsilon_{\mathrm{pl}}=\mathbf{0 . 0 2 6}$

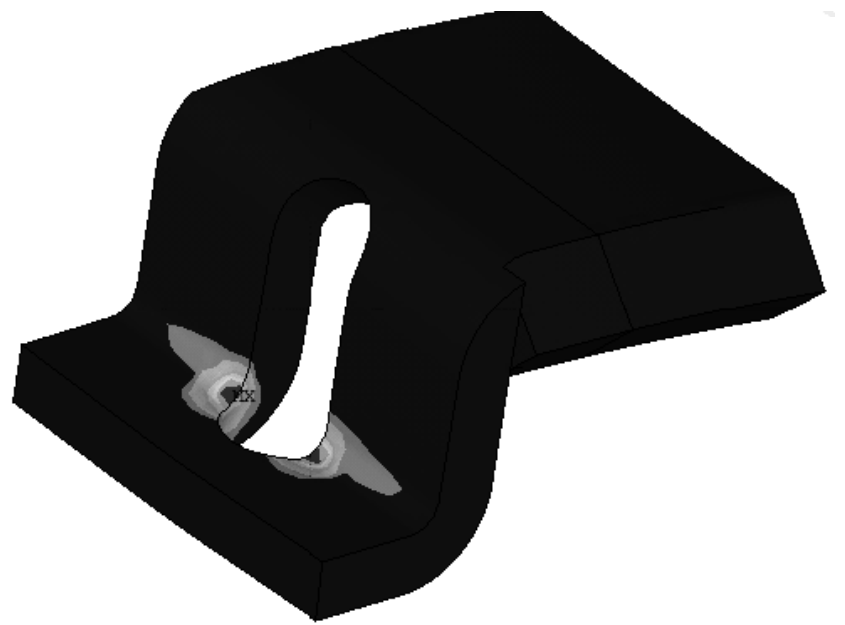

Figure 8 Plastic areas on upper yoke, $\varepsilon_{\mathrm{pl}}=\mathbf{0 . 2 4}$

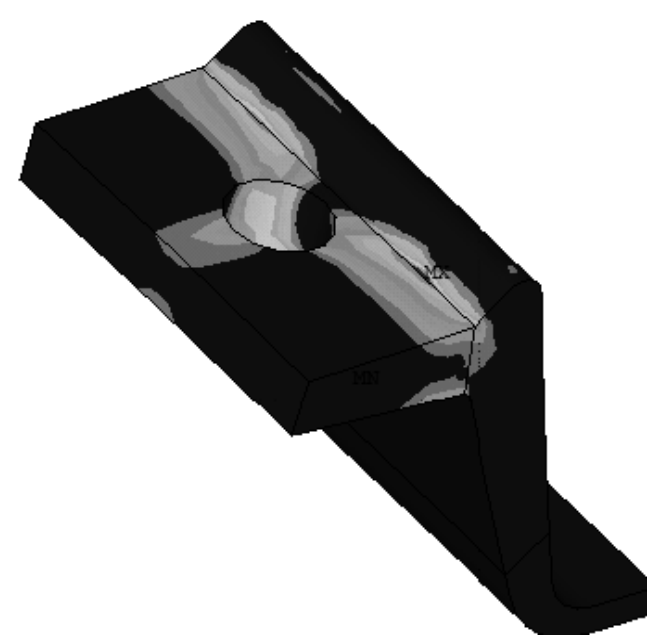

Figure 9 Plastic areas on lower yoke, $\varepsilon_{\mathrm{pl}}=\mathbf{0 . 0 4}$ 


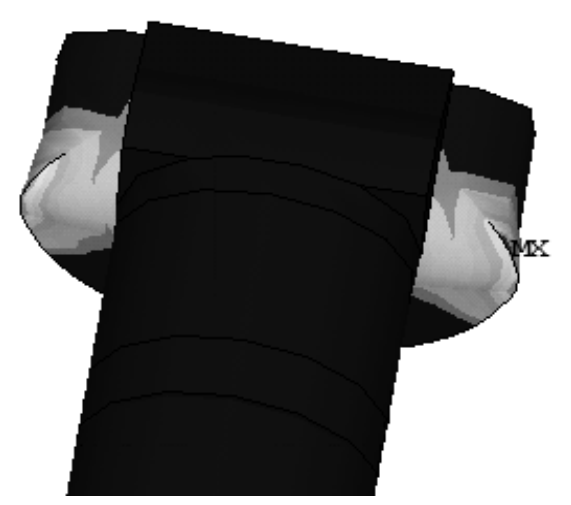

Figure $10 \quad$ Plastic areas on bolts, $\varepsilon_{\mathrm{pl}}=\mathbf{0 . 2 8}$

\subsection{Load step two - implementation of forced displacement}

The trends of the non-linear calculations are illustrated in the following two figures. The convergence calculation depending on the gradual loading is displayed in Figure 11. The second picture shows the speed of the load increment (Figure 12).

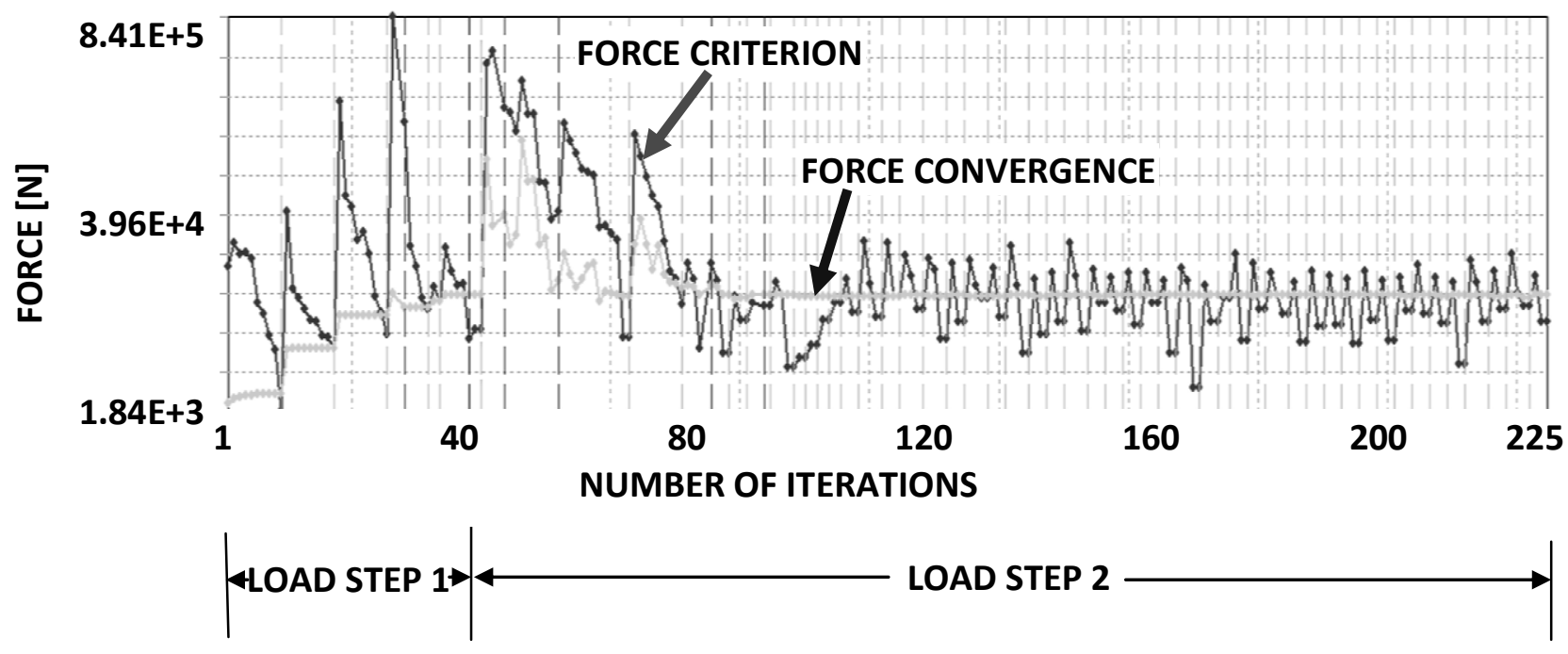

Figure 11 Typical trend of force convergence
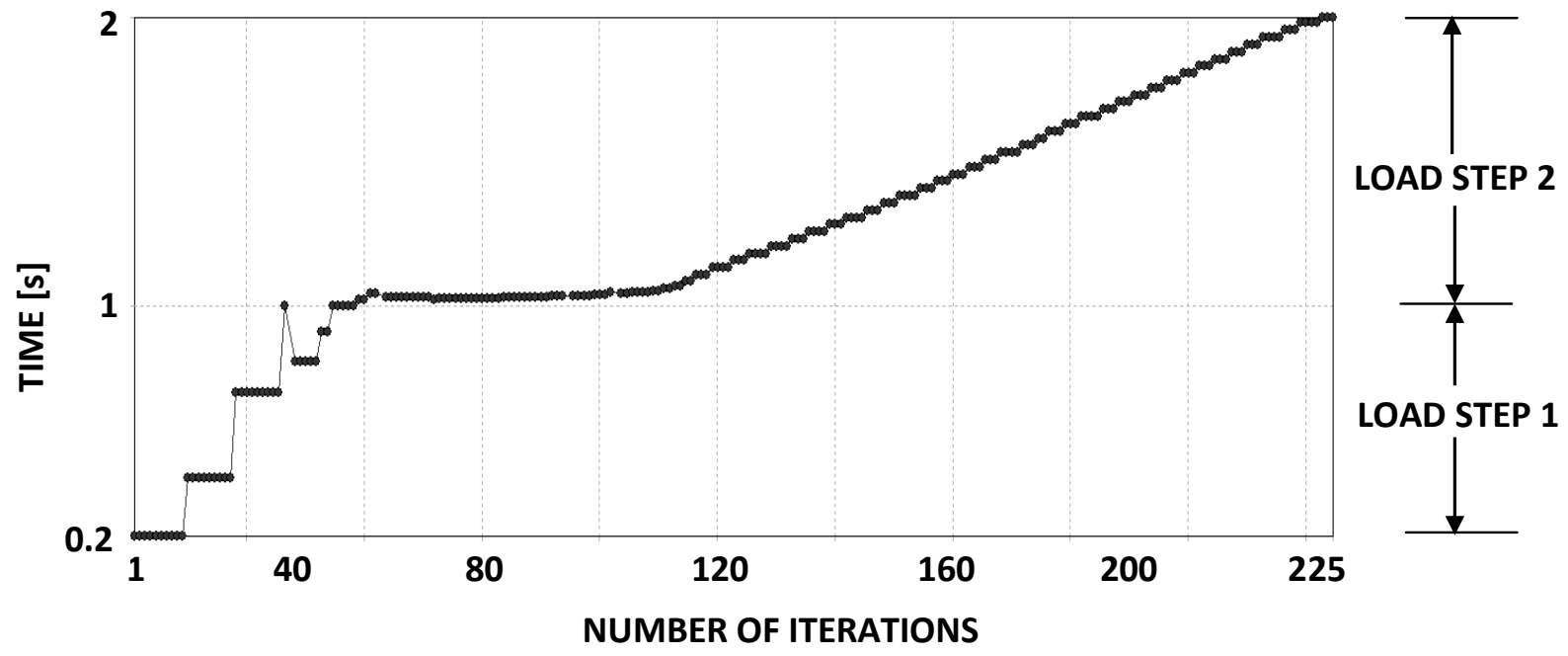

Figure 12 Speed of load increment 
Convergence in each substep of the Newton-Raphson method is satisfied when, for all nodes of the model, the force convergence condition is fulfilled. Another criterion is the increment value of equivalent plastic deformation; the maximum could be less than 0.15 . Load step one was calculated in the range of four to seven substeps, whereas the second load step was calculated in the range of 26 to 36 substeps. In each, the substeps had to be calculated with a few iterations to achieve convergence. The total number of iterations was around 230.

The main results of the numerical simulations are shown in Figure 13. Values of the critical axial force that occur when the joint is slipping are shown; here, we are speaking about the loading capacity of the yielding connection. The values are dependent on the coefficient of friction in the contacts and the values of the torque and the dependencies are shown to be almost linear.

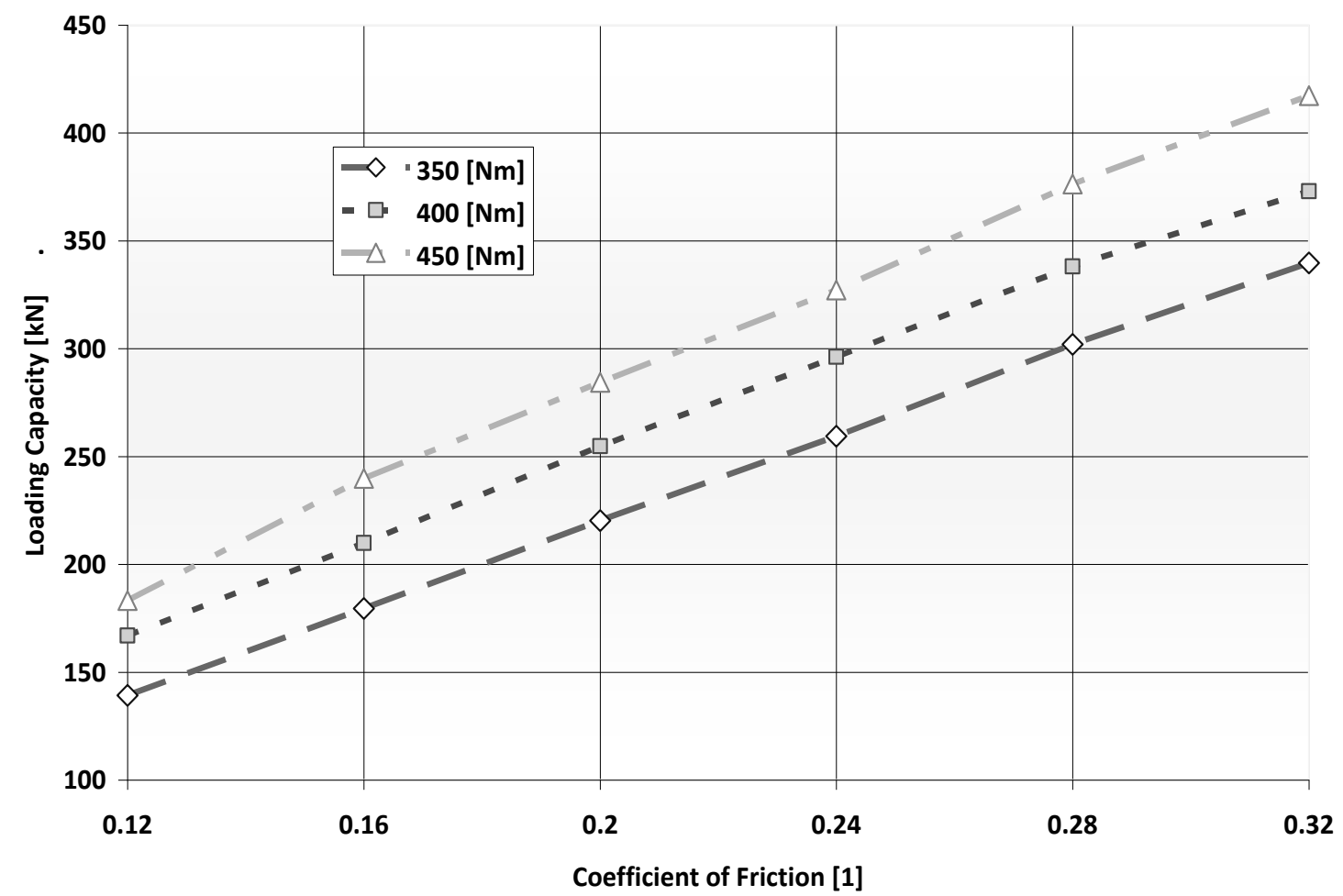

\section{Figure 13 Loading capacity of yielding connections on the values of the friction coefficient and torque}

Resistance values are consistent with those published in the literature (Šňupárek and Konečný, 2010; Janas, 1990). The range of these values and their high dependence on the coefficient of friction in the contacts has not yet been published. The minimum value of resistance was $139-350 \mathrm{Nm}$ of torque with a friction coefficient of 0.12 ; the highest value was $417-450 \mathrm{Nm}$ of torque with a friction coefficient of 0.32 .

Areas of yielding in the second load step do not change significantly. Decisive loading for the formation of plastic regions is the first load step.

\section{Conclusions}

Underground support design is mostly based on the load bearing capacity of steel arches. Optimisation of a real loading capacity of yielding supports is very important for the safe and economic design of roadways, including spacing of arches and torque of connected bolts.

Our results show that loading of the preload screw causes the creation of plastic areas in all parts of the connection. However, they are just very small areas that should not affect the functionality of the connection. 
The range of the values of loading capacity of the yielding connections and their high dependence on the coefficient of friction in the contacts based on channel profile modelling has not yet been published. The minimum value of resistance was $139 \mathrm{kN}$ with $350 \mathrm{Nm}$ of torque and a friction coefficient of 0.12 ; the highest value was $417 \mathrm{kN}$ with $450 \mathrm{Nm}$ of torque and a friction coefficient of 0.32 . The coefficient of friction of 0.12 is considered for completely new steel supports. On the other hand, the value of the coefficient of friction of 0.32 is very old corroded surface of steel supports.

It means that the quality of a steel segment surface is very important for friction resistance of a connection. The degree of corrosion of segments can influence the loading capacity in very significant way.

The paper describes results of the first stage of yielding connection modelling - modelling of straight segments. The next part, modelling of yielding arches, will bring more precise results of yielding behaviour of the roadway supports.

\section{Acknowledgements}

The paper has been undertaken in conjunction with the Institute of Clean Technologies for Mining and Utilization of Raw Materials for Energy Use, Reg. No. CZ.1.05/2.1.00/03.0082, IT4 Innovations Centre of Excellence project, Reg. No. CZ.1.05/1.1.00/02.0070, ENET CZ.1.05/2.1.00/03.0069, supported by the Operational Programme 'Research and Development for Innovations' funded by Structural Funds of the European Union and state budget of the Czech Republic and research project of the Ministry of Education, Youth and Sports of the Czech Republic No. MSM6198910027.

\section{References}

ANSYS $^{\circledR}$ Release 14.0 (2011) ANSYS ${ }^{\circledR}$ Mechanical, Help System, ANSYS, Inc.

Horyl, P. and Šňupárek, R. (2012) Reinforcing Measures of Steel Roadway Support in Rockburst Prone Areas, Archives of Mining Sciences, Vol. 57 No. 1, pp. 193-208.

Janas, P. (1990) Dimensioning of roadway supports in conditions of Ostrava-Karvina Coalfield, Strata control in deep mines, in Proceedings 11th Plenary Scientific Session of the International Bureau of Strata Mechanics/World Mining Congress, A. Kidybinski and J. Dubinski (eds), 5-9 June 1989, Novosibirsk, Russia, pp. 124-129.

Junker, M. (2009) Strata control in in-seam roadways, VGE Verlag GmbH, Essen. ISBN 978-3-86797-040-2.

Podjadtke R., Witthaus H. and Breedlove J. (2009) Development in steel roadway support - a track record, in Proceedings 27th International Conference on Ground Control in Mining, 29-31 July 2009, Morgantown, Australia, Strata Products (USA) Inc, pp. 358-365.

Šňupárek, R. and Konečný, P. (2010) Stability of roadways in coalmines alias rock mechanics in practice, Journal of Rock Mechanics and Geotechnical Engineering, Vol. 2(3) 2010, pp. 281-288. 